\title{
Investigating the Effect of Residual Stress on Hydrogen Cracking in Multi-Pass Robotic Welding through Process Compatible Non-Destructive Testing
}

\author{
Yashar Javadi $^{1 *}$, Nina E. Sweeney ${ }^{1}$, Ehsan Mohseni ${ }^{1}$, Charles N. MacLeod ${ }^{1}$, David Lines ${ }^{1}$, \\ Momchil Vasilev $^{1}$, Zhen Qiu ${ }^{1}$, Carmelo Mineo ${ }^{1}$, Stephen G. Pierce ${ }^{1}$ and Anthony Gachagan ${ }^{1}$ \\ ${ }^{1}$ Centre for Ultrasonic Engineering (CUE), Department of Electronic \& Electrical \\ Engineering, University of Strathclyde, Glasgow G1 1XQ, UK \\ *Corresponding author’s email: yashar.javadi@strath.ac.uk
}

\section{Abstract}

In this paper, the effect of Welding Residual Stress (WRS) on the size and morphology of hydrogen-induced cracks (HIC) is studied. Four samples were manufactured using a 6-axis welding robot and in two separate batches. The difference between the two batches was the clamping system used, which resulted in different amounts of welding deformation and WRS. The hydrogen cracks were intentionally manufactured in the samples using a localised waterquenching method, where water was sprayed over a specific weld pass in a predetermined position. The Phased-Array Ultrasonic Testing (PAUT) system was implemented during the welding process (high-temperature in-process method), to detect the HIC in real-time. The WRS in both batches was measured using the hole-drilling method, where a difference in transversal residual stress of 78MPa was found between the two samples. Based upon both the PAUT results and microscopic investigations, the batch with higher WRS resulted in larger size and number of HIC. For the first time, the negative effect of WRS on HIC has been monitored in real-time using high-temperature in-process inspection. This was achieved using an innovative approach, introduced in this paper, to repeatably manufacture high and low WRS samples in order to control the size and location of subsequent HIC.

Keywords: Multi-Pass Robotic Welding; Phased Array Ultrasonic Testing (PAUT); Hydrogen Induced Crack (HIC); Intentionally-Embedded Weld Defects; Welding Residual Stress (WRS); Hole-drilling Method. 


\section{Introduction}

It is known that the initiation and propagation of Hydrogen Induced Cracks (HIC), also known as cold-cracks, is influenced by three main factors: (I) hydrogen, (II) microstructure and (III) residual stress [1]. Therefore, a higher amount of hydrogen penetrating into the weld can increase the chance of HIC, especially in a brittle structure containing a higher amount of residual stress [2]. Hydrogen induced cracking is considered a major contributor to the increase in the repair costs associated with welding processes, e.g., $£ 40$ million of costs incurred during manufacturing in the UK are due to the necessary repair of HIC [3]. Hence, it is necessary to quantify the influencing parameters on the HIC initiation and propagation using the inspection system.

In this study, the effect of residual stress on the HIC is investigated using a combination of high-temperature in-process inspection using Phased-Array Ultrasonic Testing (PAUT), robotic Non-Destructive Testing (NDT), Time-of-Flight Diffraction (TOFD) and holedrilling residual stress measurement. High-temperature in-process inspection of multi-pass welding was discussed by Lines et al [4]. They used a flexible robotic cell for real-time NDT of a weld sample which included some intentionally-embedded defects, i.e., tungsten rods [4, 5]. For PAUT, an ultrasonic array (64 elements) is used rather than a single element probe since this method is expected to have higher resolution and a better signal to noise ratio [6, 7]. The offline inspection was also carried out using the PAUT system and TOFD, which provides a 2D map of the defect positions in the weld length [8]. The resolution of PAUT scans can be enhanced using a generic acquisition method called Full Matrix Capture (FMC) combined with a post-processing technique called Total Focusing Method (TFM). This allows to potentially focus on all points influenced by the ultrasonic wave [9].

It is believed that the welding process leads to the development of significant residual stresses, the stress remaining in the component in the absence of any thermal gradient or external forces [10]. The Welding Residual Stress (WRS) can be measured by destructive methods (e.g., incremental deep hole drilling $[11,12]$ or the contour method $[13,14]$ ) or by NDT methods (e.g., ultrasonic [15-17], X-ray or neutron diffraction [11]). Among over 10 different residual stress measurement methods $[10,18]$, hole-drilling is the only method which is standardised by ASTM E837 and, as such, is usually used for verification of the other residual stress measurement methods [18-20]. Therefore, the hole-drilling method was 
chosen for use in this study to measure the WRS in the samples with intentionallymanufactured HIC.

\begin{tabular}{ccccccccccc}
\hline $\mathrm{C}$ & $\mathrm{Si}$ & $\mathrm{Mn}$ & $\mathrm{P}$ & $\mathrm{S}$ & $\mathrm{Ni}$ & $\mathrm{Cr}$ & $\mathrm{Mo}$ & $\mathrm{Cu}$ & $\mathrm{V}$ & $\mathrm{Fe}$ \\
\hline $0.12 \%$ & $0.16 \%$ & $0.57 \%$ & $0.027 \%$ & $0.023 \%$ & $0.16 \%$ & $0.181 \%$ & $0.033 \%$ & $0.55 \%$ & $0.001 \%$ & Balance
\end{tabular}

In this paper, a high-temperature in-process monitoring system was used to detect the HIC intentionally manufactured during the welding process. The inspection system included a robotic arm equipped with a PAUT end-effector suitable for use in temperatures up to [150 C]. Other non-contact NDT techniques such as thermography [21], electromagnetic acoustic transducer (EMAT) [22], Laser-Induced Ultrasonic Phased Array (LIPA) [23], eddy current [24] and X-ray/radiography [25], are potential alternative options for real-time inspection of welds. However, due to the lower penetration depth of eddy current (potentially a few millimetres [24]), the safety concerns surrounding radiography inspection [26], and the lower resolution of thermography [24], less matured technology of LIPA [23] and lower signal-tonoise ratio of EMAT [22, 24] when compared with the phased array ultrasonic method [24], PAUT is preferred for this work.

\section{Experimental setup}

\subsection{Samples with intentionally-manufactured hydrogen cracks}

The four samples were manufactured from S275 structural steel plates (see Table 1 for the chemical composition) with a thickness of $15 \mathrm{~mm}$ and a length of $300 \mathrm{~mm}$. The multi-pass weld included 21 passes, deposited in 7 layers, inside a $90^{\circ}$ degree V-groove and was performed using a Tungsten Inert Gas (TIG) welding process. All four samples were manufactured with the same welding parameters, listed in Table 2, and layout, shown in Figure 1. An Automatic Voltage Correction (AVC) system was used to keep the welding voltage consistent throughout with real-time communication between the robot controller and the welding machine facilitated KUKA Robot Sensor Interface (RSI) [27] whereupon the welding voltage was adjusted with a continuously varied robot Z-position to control the arc length.

Table 1. Chemical composition of S275 structural steel (based on the material certificate provided by the manufacturer) 
Table 2. Welding parameters

\begin{tabular}{|c|c|c|c|c|c|c|c|}
\hline & $\begin{array}{c}\text { AVC* set } \\
\text { voltage }(V)\end{array}$ & $\begin{array}{l}\text { Current } \\
\text { (A) }\end{array}$ & $\begin{array}{c}\text { Travel } \\
\text { Speed } \\
(\mathrm{mm} / \mathrm{min})\end{array}$ & $\begin{array}{c}\text { Wire } \\
\text { Feed } \\
\text { Speed } \\
(\mathrm{mm} / \mathrm{min})\end{array}$ & $\begin{array}{l}\text { Weaving } \\
\text { Amplitude } \\
\text { (mm) }\end{array}$ & $\begin{array}{l}\text { Weaving } \\
\text { Frequency } \\
\quad(\mathrm{Hz})\end{array}$ & $\begin{array}{c}\text { Inter-pass } \\
\text { Temperature } \\
\left({ }^{\circ} \mathrm{C}\right)\end{array}$ \\
\hline $\begin{array}{c}\text { Pass } 1 \\
\text { (root pass) }\end{array}$ & 12 & 120 & 50 & 910 & 2 & 0.3 & $80-100$ \\
\hline $\begin{array}{c}\text { Pass } 2 \\
\text { (hot pass) }\end{array}$ & 13.5 & 220 & 100 & 1225 & 4 & 0.6 & $80-100$ \\
\hline $\begin{array}{c}\text { Pass 3-16 } \\
\text { (filling passes) }\end{array}$ & 13.5 & 210 & 120 & 1470 & 3 & 0.55 & $80-100 * *$ \\
\hline $\begin{array}{c}\text { Pass } 17-21 \\
\text { (capping passes) }\end{array}$ & 13.5 & 240 & 100 & 1225 & 4 & 0.6 & $80-100$ \\
\hline $\begin{array}{l}\text { * Automatic Voltag } \\
\text { ** Inter-pass temp } \\
\text { inspection of the la } \\
\text { leading to much lov }\end{array}$ & $\begin{array}{l}\text { orrection (A } \\
\text { ature depend } \\
\text { osition) with } \\
\text { inter-pass te }\end{array}$ & $\begin{array}{l}\text { using } t \\
\text { the in } \\
\text { exceptio } \\
\text { erature }\end{array}$ & $\begin{array}{l}\text { RSI. } \\
\text { ection time } \\
\text { f the Pass } 9 \\
\text { ear the room }\end{array}$ & $\begin{array}{l}\text { as the subse } \\
\text { fter which th } \\
\text { emperature }\end{array}$ & $\begin{array}{l}\text { uent weld po } \\
\text { localised wat } \\
\text { pecially over }\end{array}$ & $\begin{array}{l}\text { starts imme } \\
\text {-quenching to } \\
\text { e quenched }\end{array}$ & $\begin{array}{l}\text { iately after the } \\
\text { k a few minutes } \\
\text { ea). }\end{array}$ \\
\hline
\end{tabular}

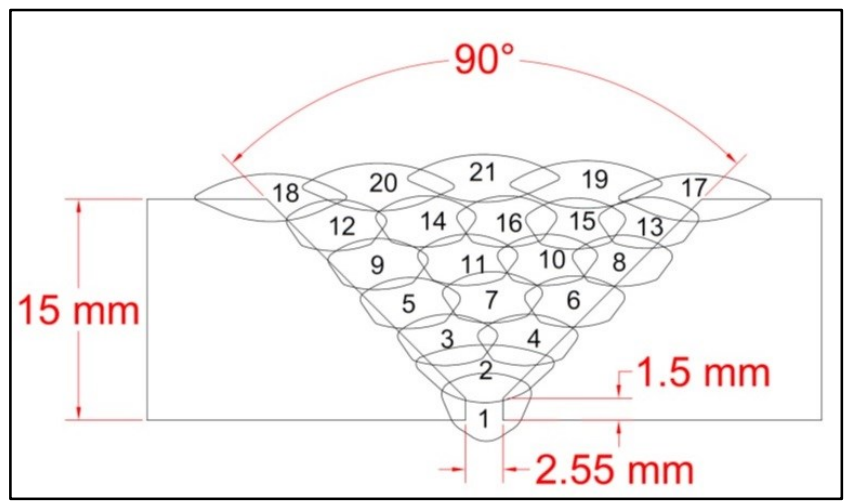

Figure 1. Welding layout and pass sequence used in this study

97 The welding wire was intentionally selected to be a hard material (i.e., hard-facing wire) to

98 increase the probability of forming a HIC in the pre-determined position. This is a high carbon wire $(0.5 \% \mathrm{C}, 3 \% \mathrm{Si}, 0.5 \% \mathrm{Mn}, 9.5 \% \mathrm{Cr}$ and $\mathrm{Fe}$ : balance $)$ with a carbon equivalent

100 (CE) higher than 0.4, meaning that it is more likely to form a martensitic brittle weld which

101 will be prone to hydrogen cracking, especially with the existence of high WRS [28].

102 A localised water quenching process was carried out directly after the deposition of Pass 9 in 103 order to introduce hydrogen into the weld site. The process is known as localised-quenching 104 since water is sprayed only after a specific pass and within only a small (40 mm) section of 
the weld length (rather than over the full length of the weld). Water absorbers were used to limit the quenching area and avoid any water spreading to other sections of the weld.

\subsection{Manufacturing of high-stress and low-stress samples}

108 Four specimens were manufactured in two batches as shown in Figure 2. Javadi et al [19]

109 showed that the position of clamps during the welding of stainless steel plates can influence

110 the amount of residual stress and deformation. Therefore, Batch $1 \& 2$ were manufactured

111 with different positioning of the clamps and seating plates as shown in Figure 2. This resulted

112 in a considerable difference in the angular shrinkage (47 $\mathrm{mm}$ in Batch 1 against only $14 \mathrm{~mm}$

113 in Batch 2) which is due to the difference in the degree of freedom between two batches.

114 During the welding of Batch 1, the weld area could move down (due to the lack of seating

115 plates next to the weld) while the corners could move up (due to the lack of clamps in the

116 corners). These factors cause extensive angular shrinkage. It can be expected that there will

117 be lower residual stresses present in Batch 1 (since some WRS can be released in the form of

118 plastic deformation [10, 17, 19, 29]) when compared with Batch 2 where the deformation was

119 restricted by tight clamping and effective seating plate placement, see Figure 2. However, this

120 expected difference in the WRS must be proven using the residual stress measurement which

121 was carried out by the hole-drilling method in this study.

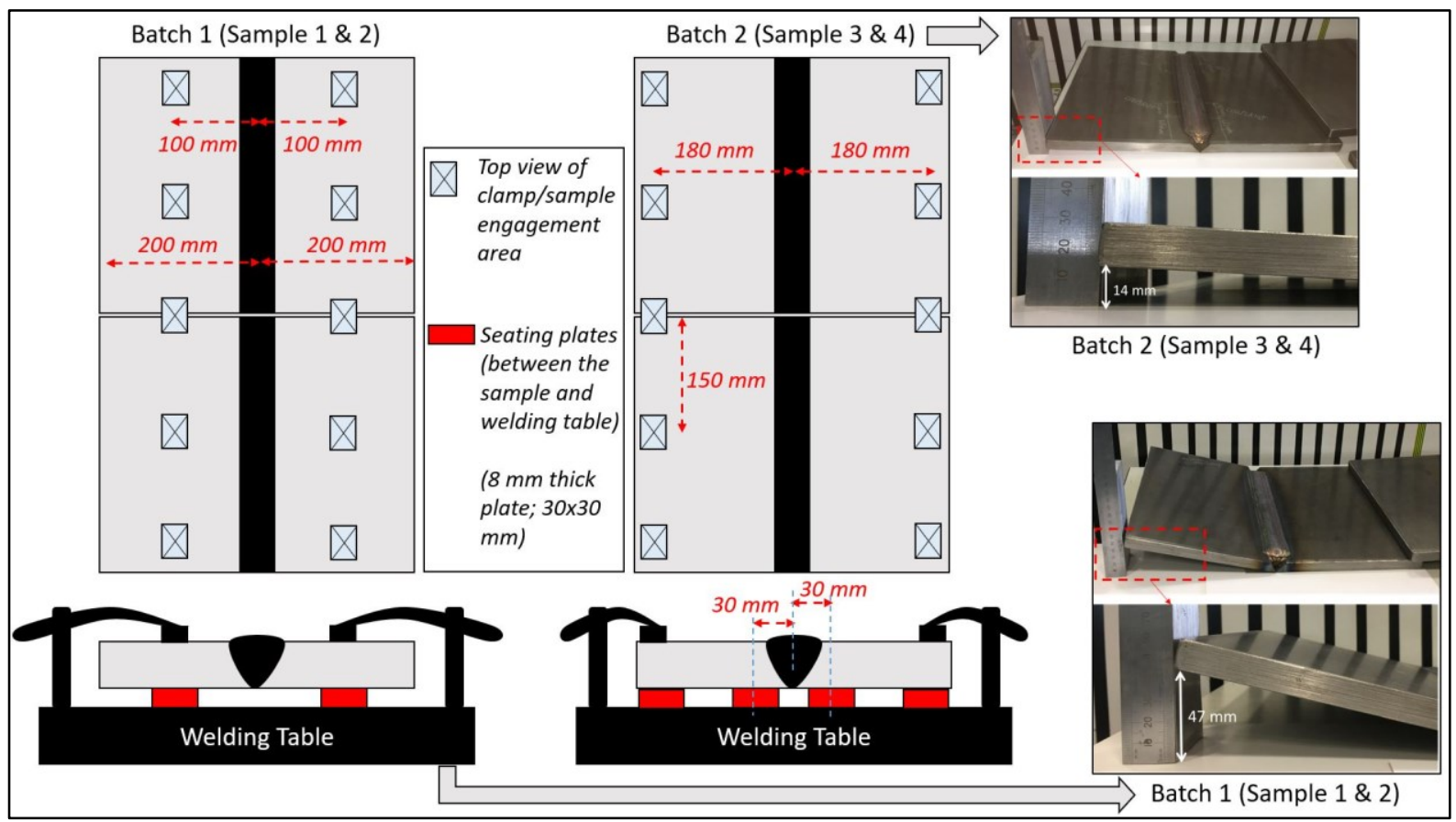

Figure 2. Welding and clamping design to manufacture high-stress and low-stress samples 


\subsection{Hole-drilling stress measurement and microscopic investigations}

126 Since both samples in each batch were manufactured using the same process parameters, and

127 the welding was carried out through a repeatable, fully robotic system, no difference between 128 samples from the same batch was anticipated. Therefore, one sample from each batch was sent for residual stress measurement using the hole-drilling method and the remaining samples were sent for metallography (see Figure 3).

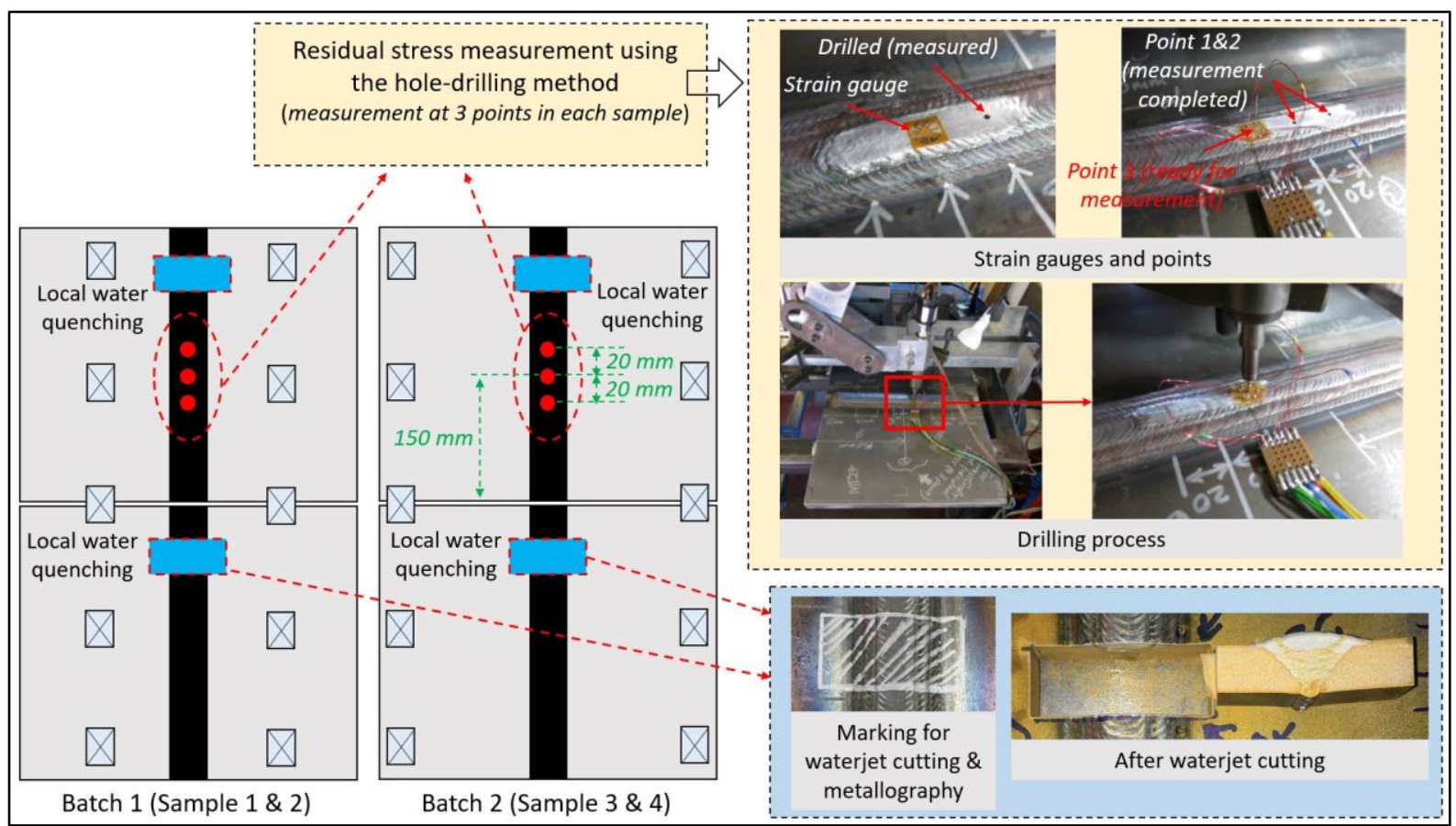

Figure 3. Position and setup for the residual stress measurement and metallography

133 The hole-drilling process [30] was carried out based on ASTM E837, in three positions on each sample. The first point is taken to be central with respect to both the weld length and width while two further points are taken in order to increase the accuracy of the overall measurement. The distance between the points is $20 \mathrm{~mm}$ to avoid the surface preparation effect of one point interfering with the other points. The hole-drilling procedure includes drilling a hole incrementally at each point, a strain gauge bonded to the surface measures the strain at each increment [31]. These strains can be related to the amount of residual stress which is released in the form of deformation [31]. The material properties of the weld,

141 deposited using the hard-facing wire, were as follows: Young's modulus of $205 \mathrm{GPa}$ and 142 Poisson's ratio $(\mu)$ of 0.295 . After surface preparation, the strain gauges were bonded such 143 that each gauge was orientated with element 1 in the weld direction and element 3 in the transverse direction (perpendicular to the weld). Holes were drilled at 16 depth increments set 
145 at $4 \times 32 \mu \mathrm{m}+4 \times 64 \mu \mathrm{m}+8 \times 128 \mu \mathrm{m}$ to give a completed hole depth of $1.4 \mathrm{~mm}$. All gauge

146 mounting and drilling procedures were conducted in accordance with the National Physical

147 Laboratory good practice [31, 32].

148 The remaining sample from each batch was marked for cutting, based on off-line ultrasonic 149 inspection results, within the local-quenching area where the HIC is expected to be observed

150 clearly (see Figure 3). The marked area was first removed using a water-jet cutting process, 151 however, due to the high hardness of the weld material, extra surface preparation (milling

152 with carbide tools and grinding) was necessary before the metallography. The samples were 153 then etched for 20 seconds using a mixture of nitric acid (one part) and ionised water (three 154 parts).

\subsection{Robotic welding and high-temperature in-process inspection system}

157 Both Batch 1 and 2 were manufactured using a robotic welding process in which a TIG

158 source was used (see Figure 4). The welding process was monitored using a high dynamic

159 range camera. The inspection process was also carried out by a 6-axis KUKA robot to

160 implement PAUT and visual inspection of the weld surface as shown in Figure 4. The

161 inspection end-effector included a $5 \mathrm{MHz}$ ultrasonic array (64 elements) mounted on a high-

162 temperature wedge (Olympus ULTEM wedge) and an inspection camera. Although a high-

163 temperature gel-couplant (Olympus high-temperature couplant) was used between the wedge

164 and rubber, no couplant was used between the rubber and the specimen surface. This dry-

165 couplant inspection technique was critical to avoid any couplant contaminating the weld site

166 unintentionally and causing uncontrollable weld-defects. Since the inspection end-effector

167 was equipped with high-temperature devices (high-temperature wedge, couplant and rubber),

168 it was possible to carry out the inspection process between the deposition of the welding

169 passes (i.e., when the specimen surface temperature is $<150{ }^{\circ} \mathrm{C}$ ). This allowed for real-time

170 PAUT sector-scanning of the hydrogen crack initiation and growth. 


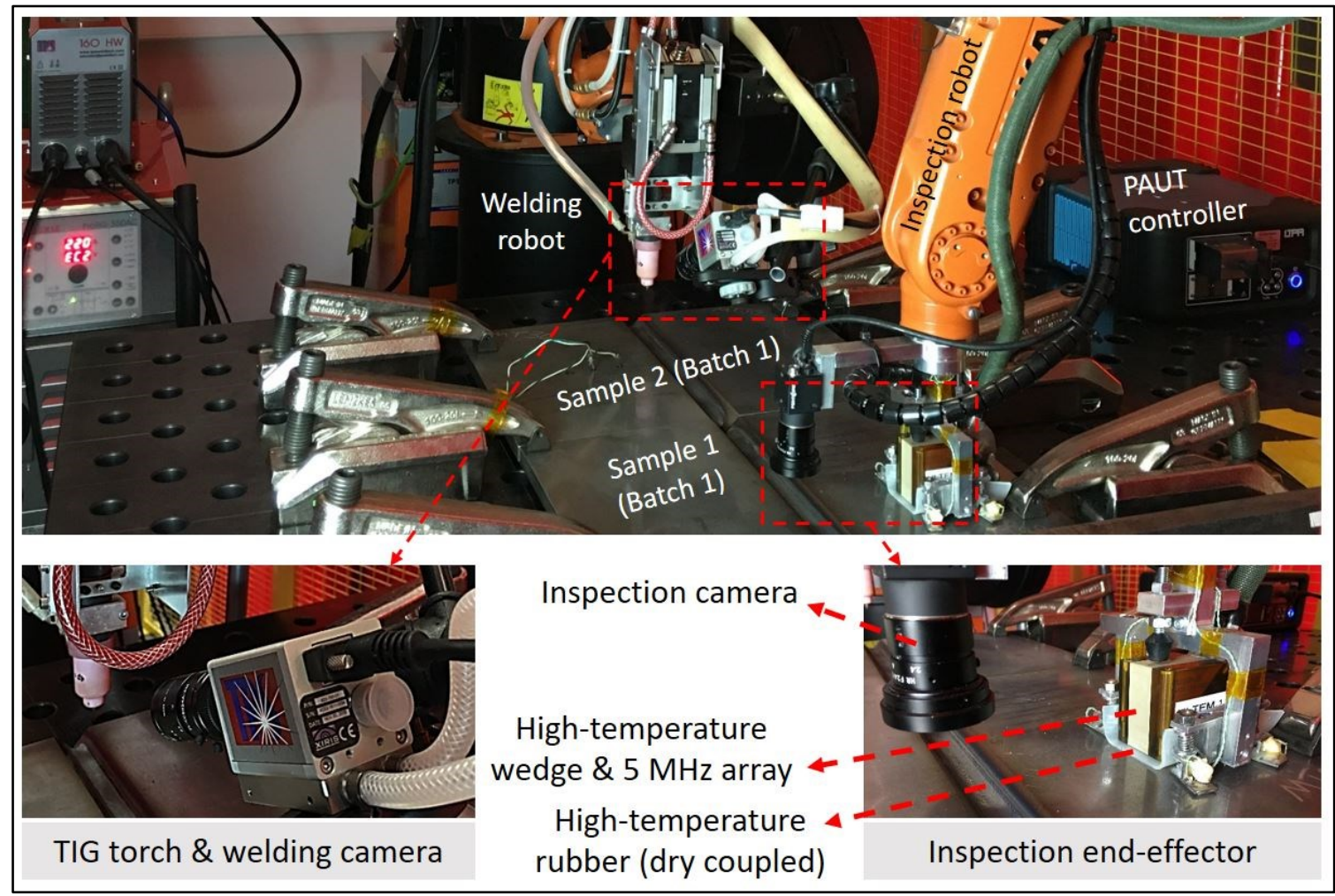

Figure 4. Robotic welding and high-temperature in-process inspection system

\subsection{Offline inspection (PAUT and TOFD)}

175 The samples were tested using PAUT (5 MHz array, high-temperature wedge and couplant)

176 and TOFD as shown in Figure 5. The PAUT imaging approach included both sector scanning

177 and also post-processing, i.e., TFM. The accuracy of this offline process was critical in order

178 to exactly mark the samples for metallography because the small cracks and subsequent

179 narrow defect area could be accidentally removed during the heavy machining required for

180 surface preparation of this hard-facing wire. 


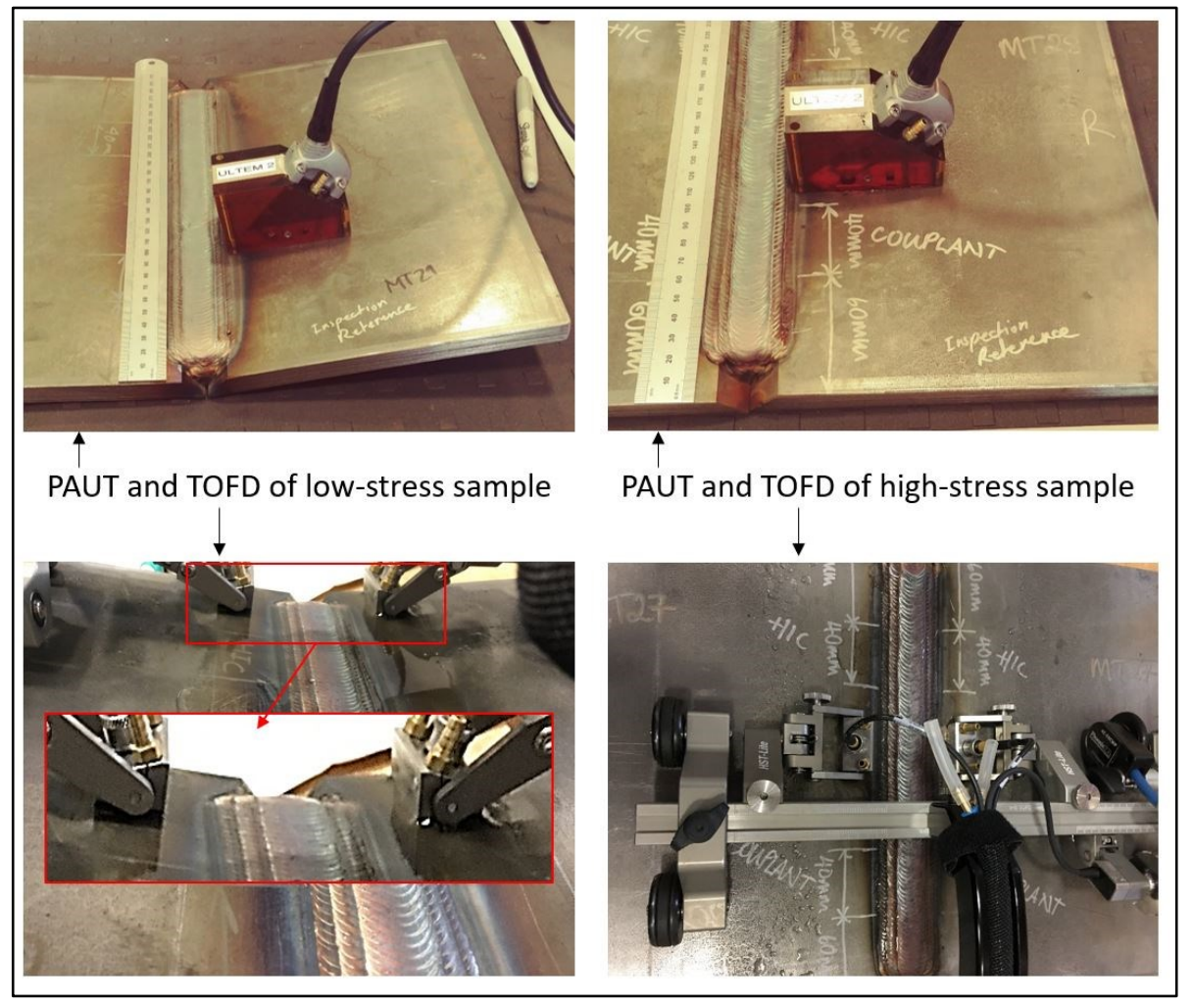

Figure 5. Inspection using PAUT (sector scanning) and TOFD

\section{Results and discussions}

\subsection{High-temperature in-process inspection results}

186 Each of the four samples manufactured in this work was inspected in three inspection

187 positions after each of the 21 welding-passes. The inspection positions were selected in a way

188 that covered both the localised water-quenching area and areas which were considered defect-

189 free. There were some obvious reflectors detected by the high-temperature PAUT system and

190 they were captured by the welding and inspection cameras as well (see Figure 6). It is worth

191 mentioning that these cracks were only observed in Batch 2 (high-stress samples) while none

192 of the three inspection devices (PAUT, welding camera and inspection camera) detected any

193 obvious cracks in Batch 1 (low-stress samples). However, this does not mean that there were

194 no cracks manufactured in Batch 1 since two of three inspection devices (i.e., welding and

195 inspection camera) can only capture surface cracks. Therefore, it is possible that some

196 internal cracks were produced in Batch 1 but were small enough in size that the high-

197 temperature PAUT resolution was not high enough to detect them. This can be proven either 


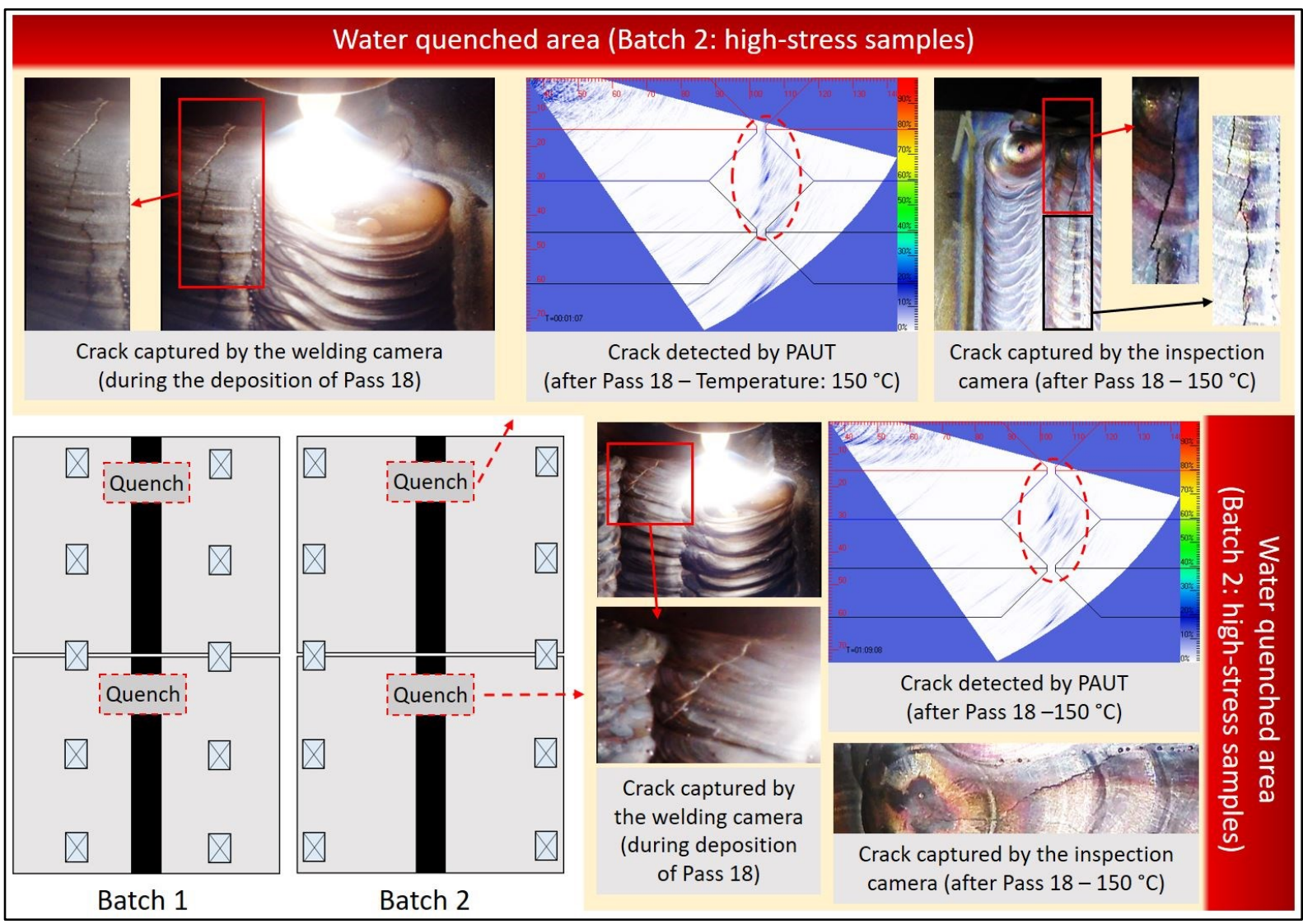

Figure 6. High-temperature in-process inspection of the crack in Batch 2 (high-stress samples)

\subsection{Residual stress measurements}

204 The results of residual stress measurement using the hole-drilling method are shown in Figure

205 7. It is worth noting that one sample with potentially lower stress (i.e., Batch 1), MT22 based on the annotation system of the lab hosting this work, and another with potentially higher stress (Batch 2: MT27) was sent for stress measurement. The NPL Good Practice Guide [31] lists a number of contributors to stress uncertainty, including factors arising from the component, the drilling process, the strain gauge and strain indicator. The strain gauge and

210 indicator together are the greatest sources of uncertainty in the form of noise in the strain

211 output. A random strain uncertainty in the range $\pm 3 \mu \varepsilon$ applied to the strain data of gauges

212 used in this assessment produces uncertainties of $\sim \pm 60 \mathrm{MPa}$ in near-surface $\sigma 1$ and $\sigma 3$

213 stresses. The high level of uncertainties near the surface is likely due to the practical

214 difficulties of surface preparation as a result of the high hardness associated with the hard- 
215 facing wire. This uncertainty decreases to a minimum of $\pm 11 \mathrm{MPa}$ at depth $512 \mu \mathrm{m}$ and then 216 increases again to $\pm 24 \mathrm{MPa}$ at the final increment due to sensitivity reduction. Therefore, the 217 near-surface defects are shown in a grey area in Figure 7b,c as they are not considered in this 218 paper due to the high level of uncertainty.

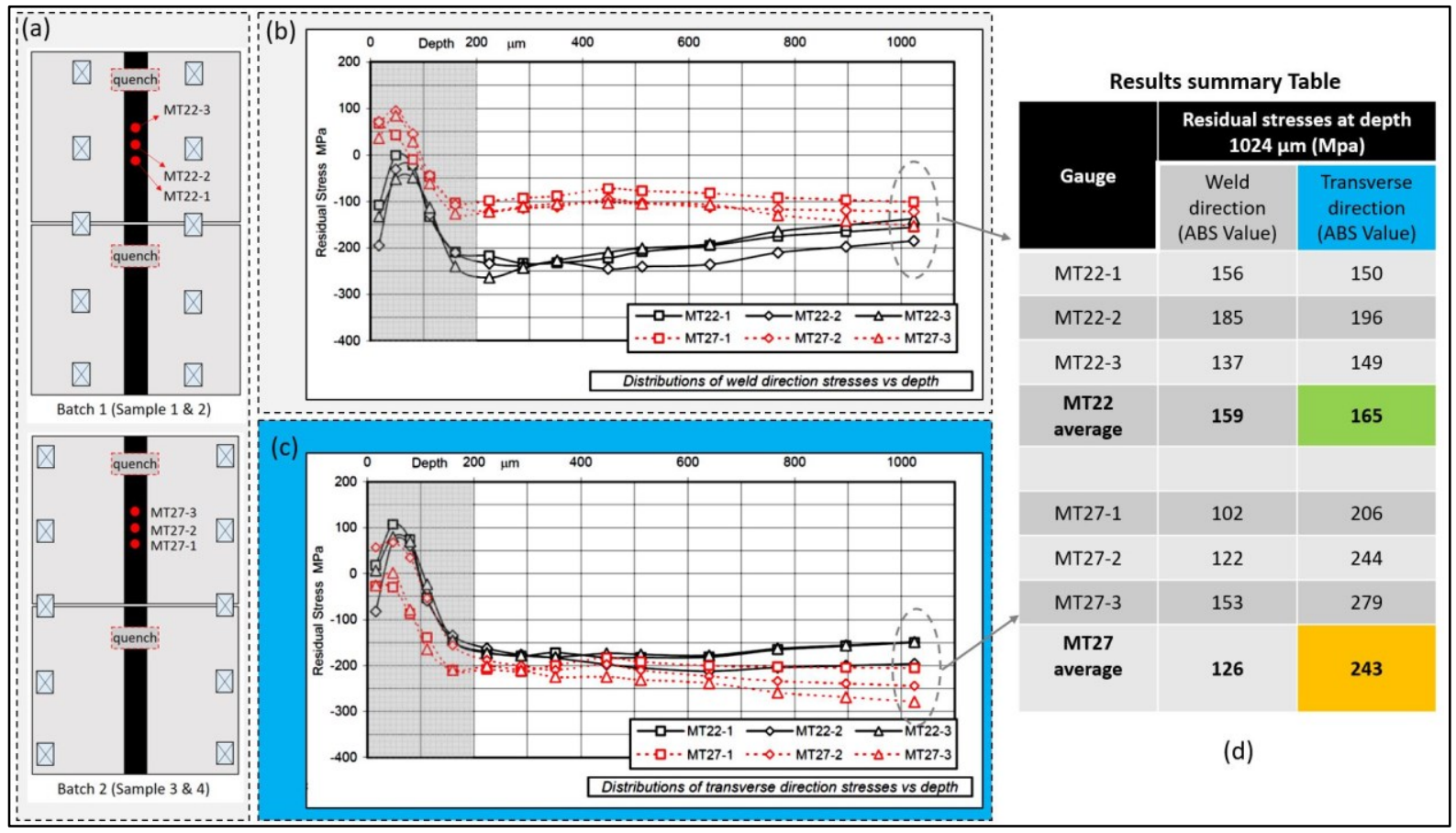

Figure 7. Residual stress measurement results (a: the measurement positions - b: residual stress in the weld direction, longitudinal stress - c: residual stress in the transverse direction, transversal stress $-\mathrm{d}$ : results summary table)

224 The average results of residual stress measured at the last increment of the hole-drilling 225 method $(1024 \mu \mathrm{m})$ are highlighted in a summary table in Figure $7 \mathrm{~d}$. These results are 226 believed to be the most relevant to the HIC since they are taken from the closest possible 227 point to the quenched area. The cracks that were captured by the inspection camera were 228 longitudinal in nature (see Figure 6) and therefore, the transversal residual stresses had the 229 main effect on the direction of crack propagation. Hence, the average value of transversal 230 residual stresses is highlighted in the summary table in Figure 7d. Results show that Batch 1 231 (MT22) residual stress reaches to the absolute value of $165 \mathrm{MPa}$ which is considerably lower 232 than Batch 2 residual stress, MT27 with $243 \mathrm{MPa}$. This proves the main idea of this paper in 233 which Batch 1 had been designed in a way to result in lower stress than Batch 2. Hence, it is 234 expected to detect smaller hydrogen cracks in Batch 1 in comparison with Batch 2. 


\subsection{PAUT, TOFD and microscopic investigation results}

237 The PAUT (sector scanning), TFM, TOFD, macrograph and microscopic investigation results

238 are shown in Figure 8. It shows an agreement between all results, i.e., stronger PAUT and

239 TFM signal are matched with stronger TOFD reflection and both are in agreement with the

240 microscopic investigations. Furthermore, all of these results are in line with the main idea of

241 this paper - proving that a large crack was detected in the sample on which higher residual

242 stress was measured. It is worth mentioning that the hydrogen crack was expected to initiate

243 from the area where the samples were quenched. This has been clearly observed in all of the

244 cracks detected in the high-stress samples.

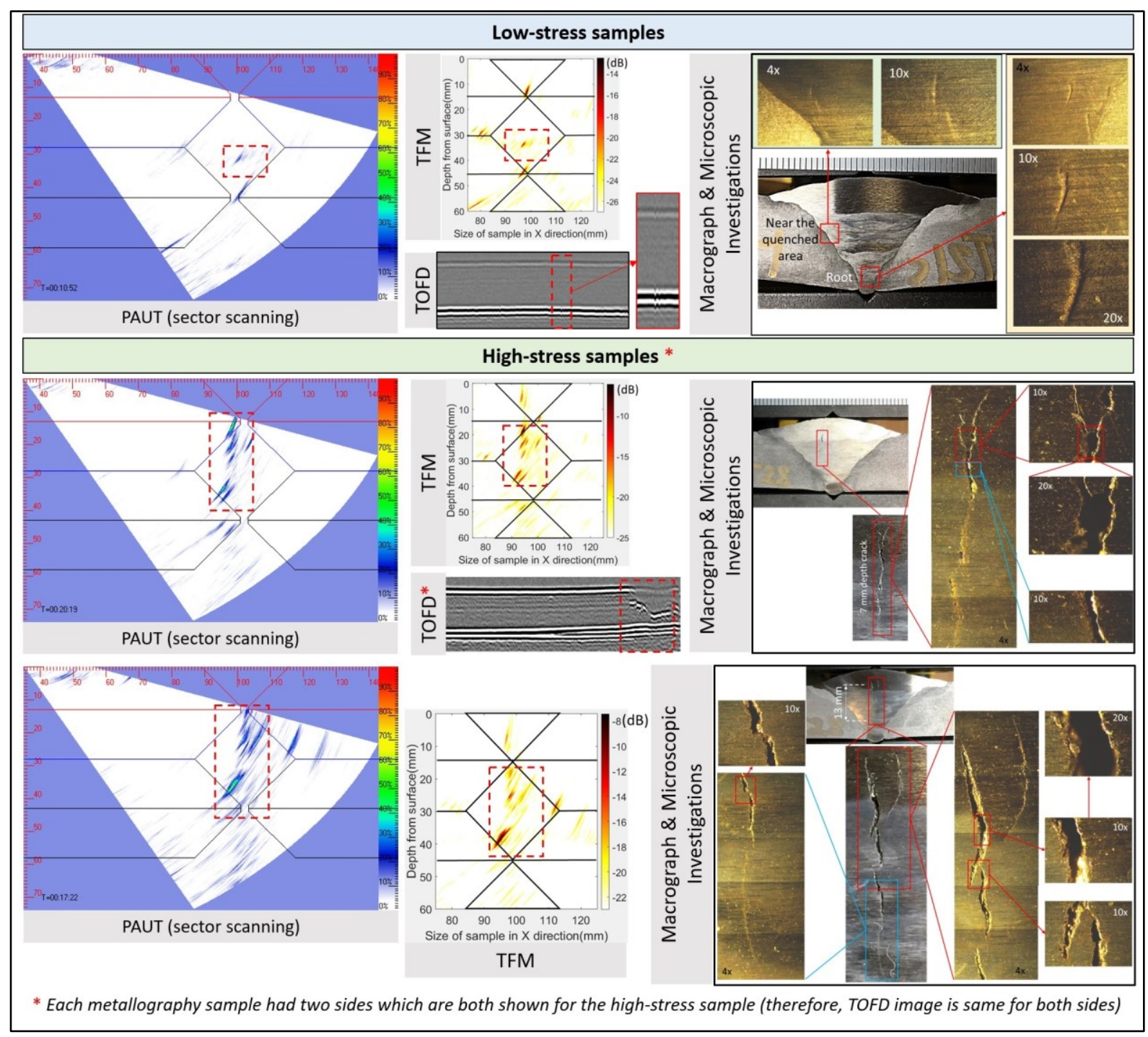


Regarding the low-stress samples, there are some signs of cracking. This is evident in the inspection results (PAUT, TOFD and TFM) where a weak reflection signal is detected (see

250 Figure 8). The macrographs also show some cracks near the quenched area and in the root

251 pass. These cracks are believed to be hydrogen cracks since they are propagated only in the $40 \mathrm{~mm}$ length of the water-quenched area while the rest of the weld length was defect-free, as proven by the TOFD inspection results (see Figure 8).

254 Finally, a very obvious difference in the length and size of HIC in the low and high-stress samples can be concluded. This was reflected in the offline inspection results (PAUT, TFM and TOFD signals) and microscopic investigations, shown in Figure 8, along with the inprocess inspections (visual camera and high-temperature PAUT system) discussed in Sec. 3.1 .

\section{Conclusions}

In this paper, a combination of phased array ultrasonic testing, TOFD, TFM, microscopic investigation, residual stress measurement, high-temperature and in-process robotic NDT was used to study the effect of welding residual stress on intentionally-manufactured hydrogen cracks. Based on the results, it can be concluded that:

1) The high-temperature in-process inspection system (PAUT, inspection and welding camera) detected a number of large cracks during the deposition of filling passes of the multi-pass welding process. However, the cracks were only visible during the welding of high-stress samples, while the low-stress samples did not show any signs of in-process cracking.

2) The residual stress measurement using the hole-drilling method proved that the clamping design was successful for manufacturing samples with high and low residual stress values (a difference of $78 \mathrm{MPa}$ was measured in the transverse direction).

3) The macrograph and microscopic investigations showed a number of very large hydrogen cracks had been intentionally manufactured in the quenched area of the high-stress sample. There are also some traces of cracks in the low-stress samples, but they are considerably smaller than the cracks propagated in the high-stress sample. 
4) The PAUT, TOFD and TFM results were in good agreement with the macrographs and microscopic investigations. Therefore, larger cracks that were subsequently detected in the macrograph had already been detected with a stronger signal in both PAUT and TOFD inspections. This was also in good agreement with the residual stress measurement results as the larger cracks (and stronger signals) were detected in the high-stress samples.

Therefore, the combination of inspection systems developed in this paper has been shown to successfully detect the negative effect which residual stress has on the structural integrity of the weld components through the development of larger hydrogen cracks. For the first time, this negative effect of WRS on HIC and the relationship between the two has been monitored in real-time using high-temperature in-process inspection. Furthermore, the achievements of this paper would not have been possible without the innovative approach developed to repeatably manufacture test samples with control over the WRS and size and location of HIC.

\section{Acknowledgements}

This work was undertaken as part of the UK Research Centre in NDE (RCNDE EP/L022125/1) core project (ABC of ARC) and also RCNDE3 core research Feasibility Project (entitled "Test Samples to Support Developments in High-Temperature In-Process Inspection"). Furthermore, the concept of high-temperature in-process inspection will be used in the Wire + Arc Additive Manufacturing (WAAM) projects which are all supported by EPSRC and InnovateUK as follows: (I) NEWAM (EP/R027218/1), (II) AIMaReM (EP/N018427/1) and (III) RoboWAAM (EP/P030165/1). The authors then like to acknowledge EPSRC, InnovateUK and RCNDE for the support and funding of the projects. The authors also like to acknowledge Dr Phil Whitehead and Stresscraft Ltd for the residual stress measurements.

\section{References}

[1] Lippold JC. Hydrogen-Induced Cracking. Welding Metallurgy and Weldability 2014. 

and mitigating hydrogen embrittlement of steels: a review of experimental, modelling and design progress from atomistic to continuum. Journal of Materials Science. 2018;53:6251-90. [3] Bailey N, Coe FR, Gooch TG, Hart PHM, Jenkins N, Pargeter RJ. Chapter 1 - Defining the problem. In: Bailey N, Coe FR, Gooch TG, Hart PHM, Jenkins N, Pargeter RJ, editors. Welding Steels Without Hydrogen Cracking (Second Edition): Woodhead Publishing; 2004. p. 1-16.

[4] Lines DI, Javadi Y, Mohseni E, Vasilev M, MacLeod CN, Vithanage RW, et al. Flexible robotic cell for in-process inspection of multi-pass welds. NDT2019: 58th Annual Conference of the British Institute of NDT. Telford, United Kingdom2019. [5] Javadi Y, MacLeod CN, Pierce SG, Gachagan A, Lines D, Mineo C, et al. Ultrasonic phased array inspection of a Wire + Arc Additive Manufactured (WAAM) sample with intentionally embedded defects. Additive Manufacturing. 2019;29:100806. Ndt \& E International. 2006;39:525-41.

[7] Javadi Y, MacLeod CN, Pierce SG, Gachagan A, Kerr W, Ding J, et al. Ultrasonic phased array inspection of wire plus arc additive manufacture (WAAM) samples using conventional and total focusing method (TFM) imaging approaches. Insight. 2019;61:144-8.

[8] Yeh FWT, Lukomski T, Haag J, Clarke T, Stepinski T, Strohaecker TR. An alternative Ultrasonic Time-of-Flight Diffraction (TOFD) method. Ndt \& E International. 2018;100:7483.

[9] Holmes C, Drinkwater BW, Wilcox PD. Post-processing of the full matrix of ultrasonic transmit-receive array data for non-destructive evaluation. Ndt \& E International. 2005;38:701-11.

[10] Withers PJ, Turski M, Edwards L, Bouchard PJ, Buttle DJ. Recent advances in residual stress measurement. International Journal of Pressure Vessels and Piping. 2008;85:118-27. [11] Javadi Y, Smith MC, Abburi Venkata K, Naveed N, Forsey AN, Francis JA, et al. Residual stress measurement round robin on an electron beam welded joint between austenitic stainless steel 316L(N) and ferritic steel P91. International Journal of Pressure Vessels and Piping. 2017;154:41-57.

[12] Mahmoudi AH, Hossain S, Truman CE, Smith DJ, Pavier MJ. A New Procedure to Measure Near Yield Residual Stresses Using the Deep Hole Drilling Technique. Experimental Mechanics. 2009;49:595-604. [13] Javadi Y, Walsh JN, Elrefaey A, Roy MJ, Francis JA. Measurement of residual stresses induced by sequential weld buttering and cladding operations involving a $2.25 \mathrm{Cr}-1 \mathrm{Mo}$ substrate material. International Journal of Pressure Vessels and Piping. 2017;154:58-74. [14] Prime MB, Hill MR, DeWald AT, Sebring RJ, Dave VR, Cola MJ. Residual stress mapping in welds using the contour method. Trends in Welding Research, Proceedings. 2003:891-6.

[15] Javadi Y, Ashoori M. Sub-surface stress measurement of cross welds in a dissimilar welded pressure vessel. Materials \& Design. 2015;85:82-90.

[16] Javadi Y, Akhlaghi M, Najafabadi MA. Using finite element and ultrasonic method to evaluate welding longitudinal residual stress through the thickness in austenitic stainless steel plates. Materials \& Design. 2013;45:628-42.

[17] Javadi Y. Investigation of Clamping Effect on the Welding Residual Stress and Deformation of Monel Plates by Using the Ultrasonic Stress Measurement and Finite Element Method. Journal of Pressure Vessel Technology-Transactions of the Asme. 2015;137.

[18] Rossini NS, Dassisti M, Benyounis KY, Olabi AG. Methods of measuring residual stresses in components. Materials \& Design. 2012;35:572-88. 
[19] Javadi Y, Hasani M, Sadeghi S. Investigation of Clamping Effect on the Welding Subsurface Residual Stress and Deformation by Using the Ultrasonic Stress Measurement and Finite Element Method. Journal of Nondestructive Evaluation. 2015;34.

360 [20] Javadi Y, Akhlaghi M, Najafabadi MA. Nondestructive Evaluation of Welding Residual Stresses in Austenitic Stainless Steel Plates. Research in Nondestructive Evaluation. 2014;25:30-43. Monitoring of Weld Pool during GTAW using Infra-Red Thermography and analysis of Infra-Red thermal images. Welding in the World. 2011;55:83-9. [22] Latham WM, MacLauchlan DT, Geier DP, Lang DD. EMAT weld inspection and weld machine diagnostic system for continuous coil processing lines: SPIE; 1996.

368 [23] Stratoudaki T, Javadi Y, Kerr W, Wilcox PD, Pieris D, Clark M. Laser Induced Phased

369 Arrays for remote ultrasonic imaging of additive manufactured components. 57th The British Institue of Non-destructive Testing Annual Conference. Nottingham, United Kingdom: The British Institue of Non-destructive Testing (BINDT); 2018. p. 10.

[24] Shull PJ. Nondestructive evaluation: theory, techniques, and applications: CRC press; 2002.

[25] Sun Y, Bai P, Sun HY, Zhou P. Real-time automatic detection of weld defects in steel pipe. Ndt \& E International. 2005;38:522-8.

[26] Cawley P. Non-destructive testing - current capabilities and future directions. Proceedings of the Institution of Mechanical Engineers Part L-Journal of Materials-Design and Applications. 2001;215:213-23.

[27] KUKA. KUKA RobotSensorInterface (RSI) 3.2 Documentation . In: KUKA, editor. Version: KST RSI 32 V12013.

[28] Vergani L, Colombo C, Gobbi G, Bolzoni FM, Fumagalli G. Hydrogen Effect on Fatigue Behavior of a Quenched\&tempered Steel. Procedia Engineering. 2014;74:468-71. [29] Francis JA, Bhadeshia HKDH, Withers PJ. Welding residual stresses in ferritic power plant steels. Materials Science and Technology. 2007;23:1009-20.

[30] Schajer GS, Whitehead PS. Hole Drilling and Ring Coring. In: Schajer GS, editor. Practical Residual Stress Measurement Methods: BLACKWELL SCIENCE PUBL, OXFORD, ENGLAND; 2013.

[31] Grant PV, Lord JD, Whitehead PS. National Physical Laboratory Good Practice Guide No. 53 Issue 2. The measurement of Residual Stresses by the Incremental Hole Drilling Technique. UK: National Physical Laboratory; 2006.

[32] Whitehead PS. Stresscraft Ltd; Methods and Techniques. The determination of residual stresses using the target gauge/centre hole drilling technique. UK: Stresscraft Ltd; 2018. 